W. D. Helenbrook ${ }^{1,2}$, N. A. Linck ${ }^{3}$, M. A. Pardo ${ }^{4}$, and J. A. Suarez ${ }^{2}$

\title{
2 Spatial variation in black-headed night monkey (Aotus nigriceps) vocalizations
}

$3{ }^{1}$ State University of New York College of Environmental Science and Forestry (SUNY-ESF), 1 Forestry Drive,

4 Syracuse, New York, United States; ${ }^{2}$ Tropical Conservation Fund, 760 Parkside Trl NW, Marietta, Georgia, USA;

$5 \quad{ }^{3}$ University of Minnesota Twin-Cities, St. Paul, Minnesota, USA; ${ }^{4}$ Cornell University, 215 Tower Road, Ithaca,

6 New York, USA

7 Corresponding author: William Helenbrook, 760 Parkside Trl NW, Marietta, Georgia 30064

8 wdhelenb@syr.edu, Phone 239-470-1200, Fax 315- 470-6934; ORCID ID: https://orcid.org/0000-0002-2706-3525

9

10

11

12

13

14

15

16

17

18

19

20

21

22

23

24

25

26

27

\section{Acknowledgements}

We would like to thank the Amazonian Conservation Association (ACA), Villa Carmen Biological Station, and Manu Learning Center (CREES) staff for hosting us, clearing trails, and providing valuable insight into location and behavior of groups. We are indebted to students and staff from the School for Field Studies who assisted with data collection and logistics. We carried out data collection in accordance with the legal requirements of Peru, and with permission of the Amazon Conservation Association and CREES. 
Abstract

30 Quantitative acoustic analysis has been used to decipher individual differences, population structure, and taxonomic

31 diversity in numerous primate species. We previously described three distinct call types in wild Aotus nigriceps, and

32 now assess acoustic differences in two of these call types between social groups and spatially distinct populations.

33 Acoustic parameters for both analyzed call types exhibited significant variability between groups. Similarly,

34 geographically distant field sites were acoustically distinct from one another. Several groups also used a variation of

35 a common call: a triplet $\mathrm{Ch} \mathrm{Ch}$ instead of a duplicate. Other groups made use of ultrasonic frequencies which have

36 not previously been reported in Aotus. Our results suggest that Aotus nigriceps exhibits substantial acoustic

37 variability across sites that could potentially be useful for taxonomic classification, although additional

38 geographically distant populations still need to be sampled. The possibility of individual signatures also exists and

39 will require recording vocalizations from known individuals.

40 Key words: vocalizations, Aotus nigriceps, night monkey, Peru, acoustics

41

42

43

44

45

46

47

48

49

50

51

52

53

54

55 


\section{Introduction}

Primates use vocalizations to communicate about the presence of predators (Zuberbühler 2002; Schel et al. 2009), location of food sources (Slocombe and Zuberbühler 2005), nesting behavior, travel intentions and group cohesion (Boinski 1996), territorial defense (Raemaekers and Raemaekers 1985; Cowlishaw, 1992), mate assessment and pair bonding (Cowlishaw 1996; Geissmann and Orgeldinger 2000). Primate acoustic signals may also be used for kin recognition and can convey information on age, sex, body size, and rank (Salmi and Hammerschmidt 2014). The diversity of these vocal signals makes acoustics a convenient tool to explore differences among primates at various taxonomic levels.

Despite the importance of acoustic communication in primates, evidence of population level differences in primate vocalizations are relatively limited (Green 1975; Maeda and Masataka, 1987; Mitani et al., 1992; Fischer et al. 1998; Mitani et al. 1999; Delgrado 2007; Wich et al. 2008; de la Torre and Snowdon 2009; Wich et al. 2012). Acoustic variation between populations can exist for any of several reasons: divergence through cultural drift in species that learn their vocalizations (i.e. inaccurate copying transmitted vertically or horizontally), genetic drift following reproductive isolation, or local adaptation in response to sexual selection, habitat transmission properties, predation pressure, or social selection pressures (Yoktan et al. 2011).

Most evidence suggests that non-human primates are not vocal learners; however, several recent studies have found that primates can learn slight modifications to their vocalizations (Watson et al. 2015; Takahashi et al. 2017). Examining patterns of geographic variation in call structure can provide some evidence for or against the presence of vocal learning; for example, if there is a sharp acoustic divide between two spatially contiguous areas that show no evidence of genetic divergence (i.e. vocal dialects), this often suggests the presence of vocal learning.

Spatial variation in vocal characteristics within a species could be a valuable tool for addressing a variety of ecological questions. For example, primate calls can be used to distinguish species, populations, groups, and individuals (Table 1). If individuals could be distinguished from one another solely using quantitative acoustic analysis, population size could be estimated by combining acoustic analysis and line transect surveys (Terry et al. 2005; Marques et al. 2013; Kalan et al. 2015). Moreover, variation in specific call characteristics could be used to infer group membership, or be used for taxonomic classification, supplementing morphometric or genetic data. Night monkeys, Aotus spp., are a useful model for investigating patterns of acoustic variation because nocturnal and forest-dwelling species tend to rely heavily on vocalizations to communicate with one another. We 
have previously reported on the vocal repertoire of wild Aotus nigriceps, describing three calls: the Squeak, $\mathrm{Ch} \mathrm{Ch}$, and Long Trill (Helenbrook et al. 2018). In this study we focus on quantitatively comparing acoustic variation of two of these calls between groups and distant populations.

\section{Methods}

Eleven Aotus nigriceps groups were sampled (Fig.1): eight at the Villa Carmen Biological Station in Pilcopata, Peru (12 $\left.53^{\prime} 39^{\prime \prime} \mathrm{S}, 71^{\circ} 24^{\prime} 16^{\prime \prime} \mathrm{W}\right)$, and three at CREES - the Manu Learning Center, on the edge of Manu National Park $\left(12^{\circ} 47^{\prime} 22^{\prime \prime} \mathrm{S} 71^{\circ} 23^{\prime} 32^{\prime \prime} \mathrm{W}\right)$. The two field sites are separated by a low mountain range $(\sim 1143 \mathrm{~m})$ and are just over $10 \mathrm{~km}$ apart at their nearest borders. Villa Carmen has a long history of development, ecotourism and agriculture. The groups sampled near the station lived in secondary forest, often dominated by bamboo or cane, whereas groups sampled at CREES inhabited recovering clear-cut to primary rainforest where bamboo and cane were largely absent. Research groups of 3-8 observers went into the field from 5:30-7:30am and 5:30-7:30pm for a total of 28 days at Villa Carmen and nine days at CREES to collect acoustic data, times when A. nigriceps groups are known to be active near their nesting sites. Several recordings also took place during the day as part of a separate behavioral study.

A Zoom H1 Handy Recorder was coupled with a RØDE NTG-2 condenser shotgun microphone and shoe shockmount on a micro boompole at a distance varying from $2-25 \mathrm{~m}$. Digital recordings were made at $48 \mathrm{kHz}$ sampling frequency with 16 or 24-bit amplitude resolution. Acoustic analysis was conducted using Raven Pro 1.5 sound analysis software (Cornell Lab of Ornithology Bioacoustics Research Program, Ithaca, New York). Calls were digitized and measured spectrographically (DFT size 512, time resolution $3.1 \mathrm{~ms}$, Hann window with 50\% overlap). Twenty-four acoustic parameters were measured for each call (Table 2).

Inter-group differences were analyzed using non-parametric Kruskal-Wallis tests coupled with post-hoc multiple comparisons of mean ranks tests with a Bonferroni correction. A Mann-Whitney $U$ test was used to assess site differences between Villa Carmen and CREES. Stepwise discriminant function analysis was used to explore acoustic parameters that could be used to classify social groups. For model selection, a stepwise forward method was used (statistic, Wilk's Lamda) with the criteria $F_{\text {to enter }}=3.84$ and $F_{\text {to remove }}=2.71$, and a tolerance level of $<0.01$ (STATISTICA). This process was repeated for both call types separately. Variables that failed a tolerance test where 
113

114

115

116

117

118

119

120

121

122

123

124

125

126

127

128

129

130

131

132

133

134

135

136

137

138

139

validation in which $90 \%$ of the calls were randomly chosen to calculate discriminant functions, while $10 \%$ was excluded for testing. Differences between observed and expected frequencies of duplicate versus triplicate $\mathrm{Ch} \mathrm{Ch}$ calls was measured using Fisher's Exact Test. All recordings were conducted non-invasively, minimized impact on behavior, and avoided excessive disturbance, and were therefore deemed exempt from the Institutional Animal Care and Use Committee approval. All applicable international, national, and/or institutional guidelines for the care and use of animals were followed.

\section{Results}

Three vocalizations have been described in wild Aotus nigriceps populations: Squeak, $\mathrm{Ch} \mathrm{Ch}$, and Trill (Helenbrook et al. 2018). In this study, we analyzed acoustic variability for the two most common calls, the Squeak ( $\mathrm{N}=1302)$ and the $\mathrm{Ch} \mathrm{Ch}(\mathrm{N}=556$; Fig. 2). For Squeaks we only measured the dominant harmonic since it was consistently found across all sampled groups. The Trill was not used because of its rarity across most groups. At least ten calls were analzyed from each of seven night monkey groups, ranging in size from 2-5 individuals (Mean=3.7). The dominant harmonic of the Squeak ranged from a mean minimum frequency of $1591 \mathrm{~Hz}$ (Range: 74-3055 Hz; SD 470) to a mean maximum frequency of $2742 \mathrm{~Hz}$ (Range: 2010-4443; SD 252). The Ch Ch call ranged from a mean minimum frequency of $1698 \mathrm{~Hz}$ (Range: 44-9092; SD 1182) to a mean maximum frequency of $11636 \mathrm{~Hz}$ (Range: 3109-23726 Hz; SD 2538).

Acoustic measurements varied significantly between groups (Fig. 3; Table 3). Differentiation between two or more monkey groups was found for all forty-eight independent vocal characteristics ( 2 call types x 24 measurements, $\mathrm{p}<0.001)$. Discriminant function analysis distinguished among groups for both call types: Squeak (Wilks' Lambda $=0.06, \mathrm{~F}(60,6706)=81.98, \mathrm{p}<0.0000)$ and $\mathrm{Ch}$ Ch (Wilks' Lambda=0.06, F(48,2592)=42.58, p $<0.0000$ ) (Table 4 and Fig. 4). Cumulative significant functions were able to explain $87.4 \%$ of variance among groups using only Squeak calls, and $87.8 \%$ of the variance among groups using only $\mathrm{Ch}$ Ch calls. Classification accuracy was similar for both the Squeak (87.4\%) and the Ch Ch (76.4\%). Duration (90\%) and energy parameters for Squeak and $\mathrm{Ch} \mathrm{Ch}$, respectively, provided the greatest discriminatory power at the group level (Table 4).

Twelve acoustic parameters were significantly different between Villa Carmen and CREES biological field stations (Table 6). Discriminant function analysis identified seven Squeak parameters that significantly distinguished 
locations: low and high frequency, bandwidth, duration (90\%), delta time, IQR duration, and max time - the first of which contributed the greatest discriminatory power; and eight $\mathrm{Ch}$ Ch parameters significantly distinguished locations: low and high frequencies, bandwidth, energy, peak frequency, Q1 frequency, frequency $(5 \%)$ and center time- the last of which contributed the greatest discriminatory power. The two sites were found to be significantly different based on Squeak (Wilks' Lambda=0.77, F(13,1281)=29.09; p<0.0000) and Ch Ch (Wilks' Lambda=0.40, $\mathrm{F}(13,526)=61.77 ; \mathrm{p}<0.0000$ ). Classification accuracy was $93.8 \%$ for Squeak (5 out of 13 CREES measurements and 116 out of 116 at Villa Carmen), and $100.0 \%$ for Ch Ch. Cumulative significant functions were able to account for $47.7 \%$ of variance between locations using the Squeak, and $77.7 \%$ using the Ch Ch call.

Other differences were observed between groups as well. The $\mathrm{Ch}$ Ch was predominately found in a series of two ("in duplicate") (88.3\% of cases); however, four groups also produced calls in triplicate (i.e. Ch $\mathrm{Ch} \mathrm{Ch}$ ). Out of 556 total Ch Ch calls, 65 were in triplicate (11.7\%), with $2.8 \%$ in T2A, $1.3 \%$ in A, $50.4 \%$ in B, and $2.8 \%$ in E. The distribution of triplicate calls across groups differed significantly from even distribution across groups, with Group B exhibiting nearly four times as many triplicates as expected $(\mathrm{p}=0.0000)$. In addition, two groups were observed using ultrasonic frequencies as part of the $\mathrm{Ch}$ Ch call $(>20 \mathrm{kHz})$ : group $\mathrm{C}(\mathrm{N}=3)$ at Villa Carmen and T2A $(\mathrm{N}=1)$ at CREES.

\section{Discussion}

The majority of acoustic parameters for both calls differed significantly between groups and geographic locations, though single acoustic parameters alone were not sufficient to predict group membership. Variance of acoustic parameters overlapped in nearby groups, making absolute classification difficult. However, there was a consistent pattern whereby calls from the same groups and population tended to cluster together based on similar acoustic measurements. Population level classification was more accurate, largely driven by acoustic parameters of the Ch Ch call. Quantitative analysis of acoustic traits may therefore be useful in elucidating group and population level differences and may provide useful insight into the underlying phylogenetic relationships between groups, populations and potentially species of Aotus. However, additional recordings are needed both at the group and population levels, preferably with more distant populations included.

We were unable to investigate individual acoustic variability because of our inability to pair calls to specific individuals in a complex environment at night. Based on various other primate studies it is likely that 
individuals can be differentiated based on vocal signatures (Table 1). However, confirmation of vocal individuality will require either analysis in captivity or pairing video and audio recordings in wild nesting groups. If recordings can be attributed to specific individuals, then acoustic analysis could be used to establish whether individual conspecifics vary predictably in their vocalizations. Establishing the ability to vocally differentiate individuals would be particularly useful for a nocturnal species such as the black-headed night monkey, allowing researchers to study group composition solely based on vocal recordings.

Aside from differences in acoustic parameters, two other acoustic differences were discovered among groups. First, a triplet $\mathrm{Ch}$ Ch call was found in recordings from groups T2A, A, B, E. Though relatively rare within the sampled populations (11.7\% of cases), over half of these cases were found in Group B. The other groups at Villa Carmen that used the triplet call are likely of the same population since they are isolated on all but one side and in relative proximity to group B $(<1300 \mathrm{~m}$ at furthest extent). The prevalence of the triplet call in Group B suggests that this is not an aberration but rather a consistent modification of a common call. The fact that the triplet call only occurred in certain groups could reflect any number of possibilities including increased prevalence of a particular behavioral context, or a vocal innovation (genetic or learned). Alternatively, it is possible that the presence of both duplicate and triplet $\mathrm{Ch} \mathrm{Ch}$ calls is the ancestral state and the absence of the triplet call is derived. Either way, additional sampling of nearby groups - coupled with underlying population genetics analysis - would confirm whether this is a relatively unique acoustic irregularity which is independent of underlying population structure, or whether this call variation routinely arises and is widespread. Likewise, being able to obtain calls specific to individuals through video and audio pairing in nests would allow us to decipher whether all individuals within a particular group use the triplet call.

It is uncertain whether the use of ultrasonic frequencies in night monkeys is rare or whether this is a common response to environmental pressures such as inter-species competition for lower frequencies or predator avoidance. Of course, other nocturnal primates (i.e., Tarsius, Galago, Microcebus, Nycticebus) and some diurnal neotropical primates (i.e., Callithrix and Cebuella) produce calls containing ultrasonic frequencies, though only the tarsiers produce calls entirely within the ultrasonic range, with the other species always producing dominant frequencies in the human audible range (Ramsier et al. 2012). In several species, the use of ultrasound appears to be context specific, often in the presence of predators, including humans (e.g. Rahlfs and Fichtel 2010; Gursky-Doyen 2013). 
Aotus currently consists of eleven described species based on both phenotypic and genotypic evidence.

197 Night monkey taxonomy has been revised considerably based on differences in karyotypes, morphology, molecular

198

The authors declare that they have no conflict of interest. population-level or species-level taxonomy.

\section{Conflict of Interest} sequencing, malaria sensitivity, immunological responses, and geographic isolation (Menezes et al. 2010). Despite this, few specimens from any one study have come from Aotus nigriceps despite this species having one of the largest ranges of any Aotus species. Moreover, the current taxonomic classification lumps A. nigriceps populations from areas with considerably different elevations and from areas separated by significant river systems. Thus, the possibility remains that further evolutionary and conservation management units may exist. Considering the distinct differences in call types previously described between Aotus species and the use of quantitative acoustic sampling to differentiate many other primate species, we anticipate that further analysis would prove useful in differentiating

Finally, Aotus nigriceps likely produce more than the three described call types since captive Aotus species have exhibited larger vocal repertoires. In captive situations it is easier to record night monkeys at close distances and calls can be induced in different situations, which could facilitate observation of a wider variety of call types. We anticipate that with continued sampling these additional call types could also be recorded in the wild.

214 References

215 Ambrose L (2003) Three acoustic forms of Allen's galagos (Primates; Galagonidae) in the Central African region.

$216 \quad$ Primates 44:25-39

217 Boinski S (1996) Vocal coordination of troop movement in squirrel monkeys (Saimiri oerstedi and S. sciureus) and 218 white-faced capuchins (Cebus capucinus). Adaptive radiations of Neotropical primates 251-269

219 Braune P, Schmidt S, Zimmermann E (2008) Acoustic divergence in the communication of cryptic species of nocturnal primates (Microcebus ssp.). BMC biology 6:1-10. 
Clink DJ, Bernard H, Crofoot MC, Marshall AJ (2017) Investigating individual vocal signatures and small-scale patterns of geographic variation in female Bornean gibbon (Hylobates muelleri) great calls. International Journal of Primatology 38:656-671

Clink DJ, Crofoot MC, Marshall AJ (2018) Application of a semi-automated vocal fingerprinting approach to monitor Bornean gibbon females in an experimentally fragmented landscape in Sabah, Malaysia. Bioacoustics 117

Cowlishaw G (1992) Song function in gibbons. Behaviour 121:131-153

Cowlishaw G (1996) Sexual selection and information content in gibbon song bouts. Ethology 102:272-284. https://doi.org/10.1111/j.1439-0310.1996.tb01125.x

de la Torre S, Snowdon CT (2009) Dialects in pygmy marmosets? Population variation in call structure. American Journal of Primatology 71: 333-342

Delgado RA (2007) Geographic variation in the long calls of male orangutans (Pongo spp). Ethology 113:487-498

Fischer J, Hammerschmidt K, Todt D (1998) Local variation in Barbary macaque shrill barks. Animal Behaviour $56: 623-629$

Garbino GS, Martins-Junior AM (2018) Phenotypic evolution in marmoset and tamarin monkeys (Cebidae, Callitrichinae) and a revised genus-level classification. Molecular Phylogenetics and Evolution 118:156-171. https://doi.org/10.1016/j.ympev.2017.10.002

Geissmann T, Orgeldinger M (2000) The relationship between duet songs and pair bonds in siamangs, Hylobates syndactylus. Animal Behaviour 60:805-809. https://doi.org/10.1006/anbe.2000.1540

Green S (1975) Dialects in Japanese monkeys: vocal learning and cultural transmission of locale-specific vocal behavior? Zeitschrift für Tierpsychologie 38:304-314

Gursky-Doyen S (2013) Acoustic characterization of ultrasonic vocalizations by a nocturnal primate Tarsius syrichta. Primates 54:293-299

Hafen T, Neveu H, Rumpler Y, Wilden I, Zimmermann E (1998) Acoustically dimorphic advertisement calls separate morphologically and genetically homogenous populations of the grey mouse lemur (Microcebus murinus). Folia Primatologica 69:342-356

Helenbrook W, Preston L, Link N, Quirk M, Suarez J (2018) Bioacoustics of the black-headed night monkey, Aotus nigriceps. Neotropical Primates 24:29-33 
Kalan A, Mundry R, Wagner OJ, Heinicke S, Boesch C, Kühl HS (2015) Towards the automated detection and occupancy estimation of primates using passive acoustic monitoring. Ecological Indicators 54:217-226. https://doi.org/10.1016/j.ecolind.2015.02.023

Macedonia JM, Taylor LL (1985) Subspecific divergence in a loud call of the ruffed lemur (Varecia variegata). American Journal of Primatology 9:295-304. https://doi.org/10.1002/ajp.1350090406

Maeda T, Masataka N (1987) Locale-specific vocal behaviour of the tamarin (Saguinus I. labiatus). Ethology 75:2530

Marques TA, Thomas L, Martin SW, Mellinger DK, Ward JA, Moretti DJ, Harris D, Tyack PL (2013) Estimating animal population density using passive acoustics. Biological Reviews 88:287-309. https://doi.org/10.1111/brv.12001

Masters, JC (1991) Loud calls of Galago crassicaudatus and G. garnettii and their relation to habitat structure. Primates 32:153-167

Menezes AN, Bonvicino CR, Seuánez HN (2010) Identification, classification and evolution of owl monkeys (Aotus, Illiger 1811). BMC Evolutionary Biology 10:248. https://doi.org/10.1186/1471-2148-10-248

Mitani JC, Hasegawa T, Gros-Louis J, Marler P, Byrne R (1992) Dialects in wild chimpanzees? American Journal of Primatology 27:233-243

Mitani JC, Hunley KL, Murdoch ME (1999) Geographic variation in the calls of wild chimpanzees: a reassessment. American Journal of Primatology 47:133-151

Nietsch A (1999) Duet vocalizations among different populations of Sulawesi tarsiers. International Journal of Primatology 20:567-583

Raemaekers JJ, Raemaekers PM (1985) Field playback of loud calls to gibbons (Hylobates lar): territorial, sexspecific and species-specific responses. Animal Behaviour 33:481-493. https://doi.org/10.1016/S0003$3472(85) 80071-3$

Rahlfs M, Fichtel, C (2010) Anti-predator behaviour in a nocturnal primate, the grey mouse lemur (Microcebus murinus). Ethology 116:429-439. https://doi.org/10.1111/j.1439-0310.2010.01756.x

Ramsier MA, Cunningham AJ, Moritz GL, Finneran JJ, Williams CV, Ong PS, Gursky-Doyen SL, Dominy NJ (2012) Primate communication in the pure ultrasound. Biol Lett 8:508-511. http:doi.org/10.1098/rsbl.2011.1149 
Salmi R, Hammerschmidt K (2014) Individual distinctiveness in call types of wild western female gorillas. PLoS ONE 9:1-13. https://doi.org/10.1371/journal.pone.0101940

Schel A, Tranquilli S, Zuberbühler K (2009) The alarm call system of two species of black-and-white colobus monkeys (Colobus polykomos and Colobus guereza). Journal of Comparative Psychology 123:136-150

Slocombe K, Zuberbühler K (2005) Functionally referential communication in a chimpanzee. Current Biology 15:1779-1784. https://doi.org/10.1016/j.cub.2005.08.068

Takahashi DY, Liao DA, Ghazanfar AA (2017) Vocal learning via social reinforcement by infant marmoset monkeys. Current Biology 27:1844-1852

Terry AM, Peake TM, McGregor PK (2005) The role of vocal individuality in conservation. Frontiers in Zoology 2:10-26. https://doi.org/10.1186/1742-9994-2-10

Watson SK, Townsend SW, Schel AM et al (2015) Vocal learning in the functionally referential food grunts of chimpanzees. Current Biology 25:495-499

Wich SA, Schel AM, De Vries H (2008) Geographic variation in Thomas langur (Presbytis thomasi) loud calls. American Journal of Primatology 70:566-574

Wich SA, Krützen M, Lameira AR et al (2012) Call cultures in orang-utans? PLoS One 7:e36180. https://doi.org/10.1371/journal.pone.0036180

Yoktan K, Geffen E, Ilany A, Yom-Tov Y, Naor A, Leader N (2011) Vocal dialect and genetic subdivisions along a geographic gradient in the orange-tufted sunbird. Behavioral Ecology and Sociobiology 65:1389-1402

Zimmermann E, Bearder SK, Doyle GA, Andersson AB (1988) Variations in vocal patterns of Senegal and South African lesser bushbabies and their implications for taxonomic relationships. Folia Primatologica 51:87-105

Zimmermann E (1990) Differentiation of vocalizations in bushbabies (Galaginae, Prosimiae, Primates) and the significance for assessing phylogenetic relationships. Journal of Zoological Systematics and Evolutionary Research 28:217-239. https://doi.org/10.1111/j.1439-0469.1990.tb00377.x

Zuberbühler K (2002) A syntactic rule in forest monkey communication. Animal Behaviour 63:293-299. https://doi.org/10.1006/anbe.2001.1914 
Fig. 1 Field research conducted at Villa Carmen Biological Station (eight black-headed night monkey groups) and CREES - Manu Learning Centre (three groups), in southeastern Peru. A mountain ridge separates the two field stations $(10.1 \mathrm{~km}$ at nearest points)

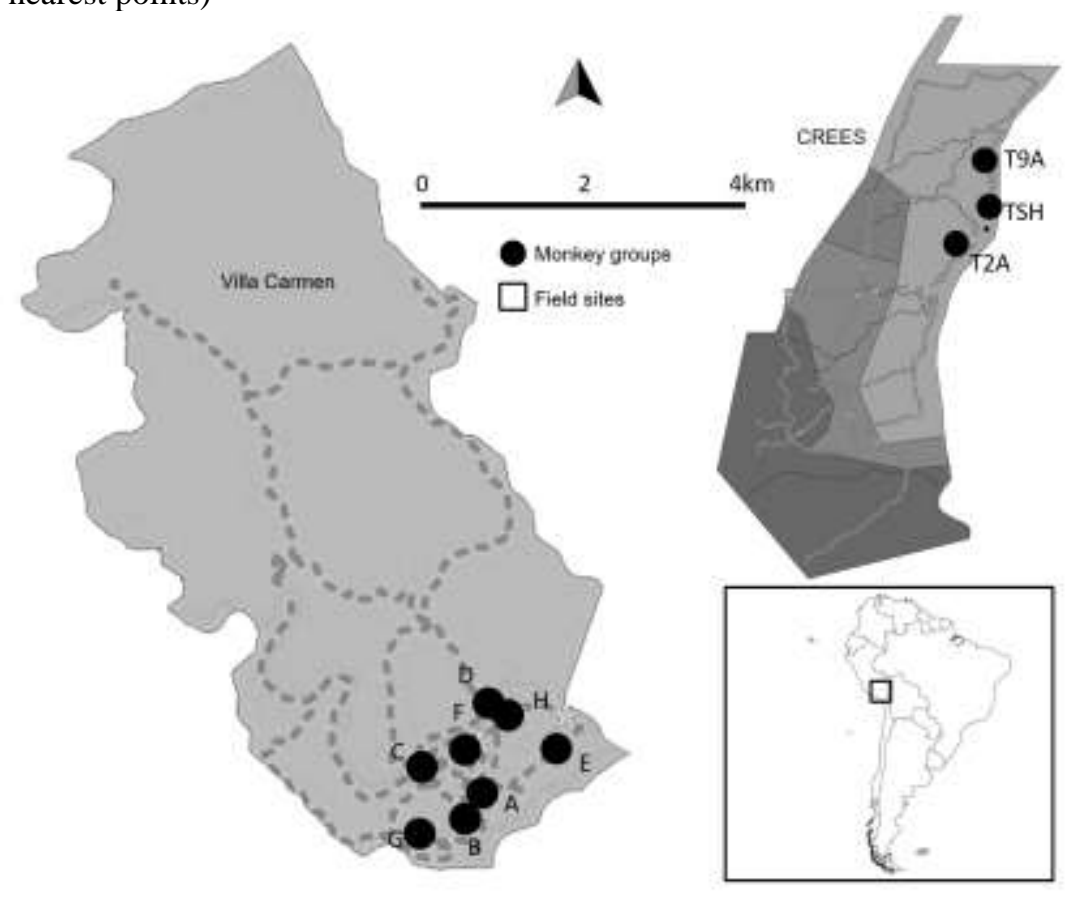

Fig. 2 Spectrogram representing both calls quantitatively analyzed in this study: the Squeak (left) and the Ch Ch (right). Both calls have been previously described (Helenbrook et al. 2018). In this example, a duplicate $\mathrm{Ch} \mathrm{Ch}$ is depicted. The upper range of the spectrogram is faint, partially a result of minimizing backgound noise in the 7-8 $312 \mathrm{kHz}$ from insects 
Fig 3 Boxplot plate of four descriptive acoustic measurements (e.g., duration, maximum frequency, minimum frequency, and bandwidth) for the Squeak and $\mathrm{Ch} C \mathrm{Ch}$ across all groups. Median represented by solid box, box plot is $25-75 \%$ of call variability, and whiskers are minimum and maximum which do not signify significance, rather distribution of values is depicted. Note that inter quartile ranges are depicted instead of standard error or deviation because of the non-parametric nature. T2A, TSH, and T9A groups are from CREES while A-H are from Villa Carmen. Significant differences illustrated in Table 3
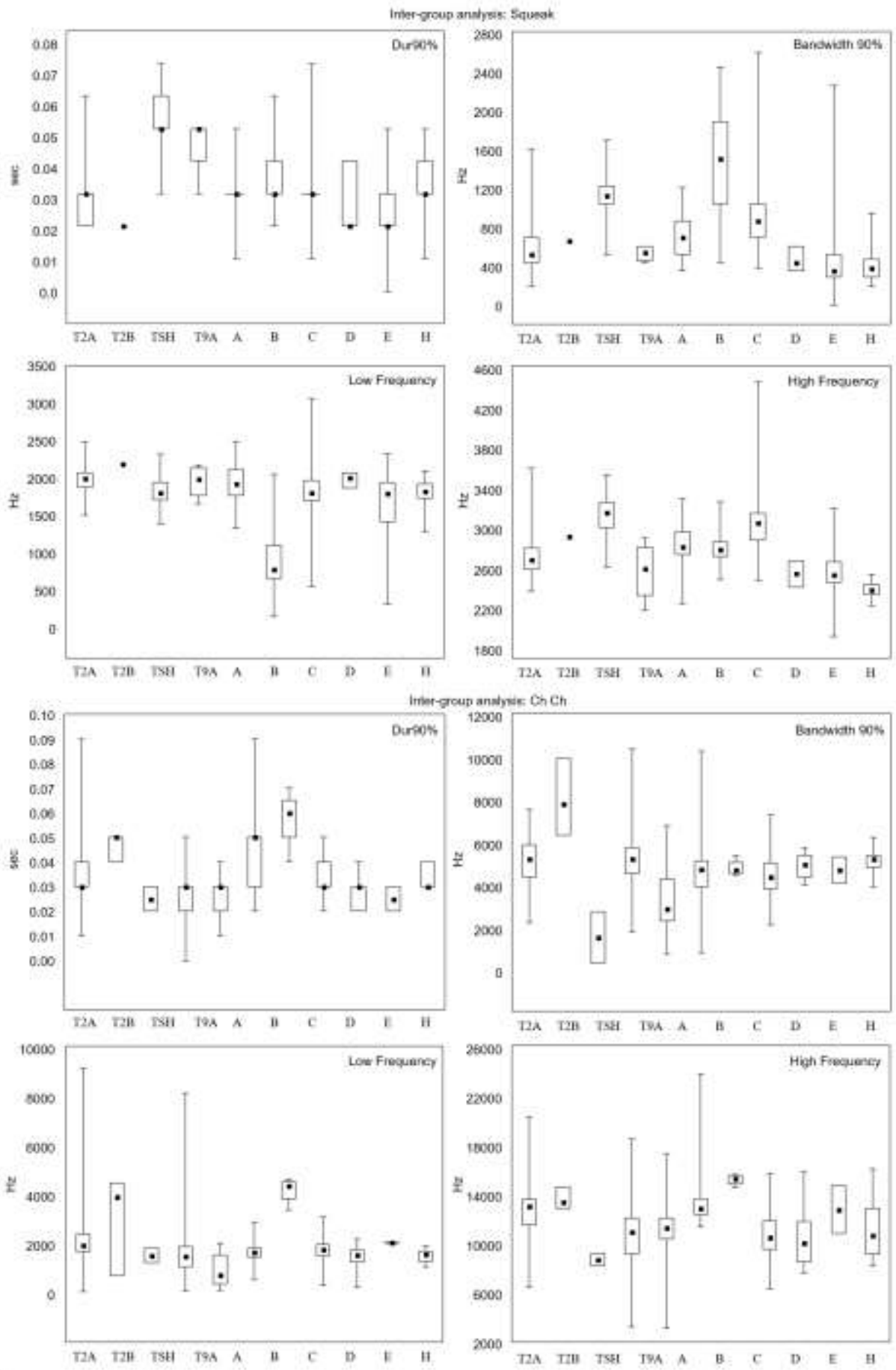
Fig 4 Canonical score scatterplot. The biplot axes are the first two canonical variables. These define the two the calls were randomly chosen to calculate discriminant functions. Here we present the results of the $10 \%$ excluded
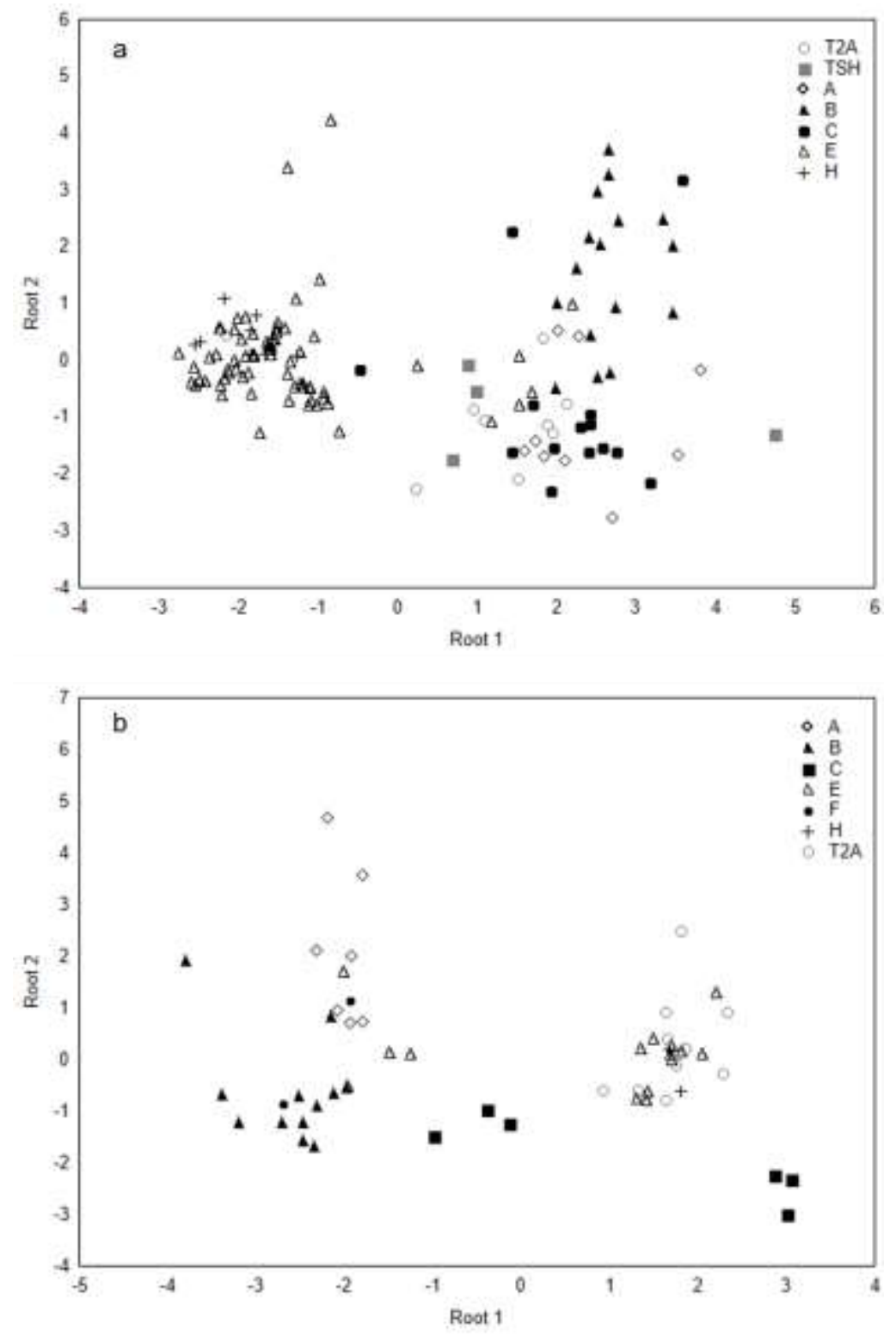
337 Table 1 Evidence of primate acoustic variation at various taxonomic levels.

\begin{tabular}{|c|c|c|c|c|c|c|c|}
\hline Primate species (N) & Individual & Group & Population & Subspecies & Species & $\begin{array}{l}\text { Call } \\
\text { description }\end{array}$ & Study \\
\hline $\begin{array}{l}\text { Cebidae, } \\
\text { Callitrichinae (28) }\end{array}$ & - & - & - & - & Yes & Long call & Garbino 2018 \\
\hline Galago spp. (8) & - & - & - & - & Yes & Loud call & $\begin{array}{l}\text { Zimmermann } \\
1990\end{array}$ \\
\hline Galago alleni & - & - & & & Yes & Loud call & Ambrose 2003 \\
\hline $\begin{array}{l}\text { Galago } \\
\text { crassicaudatus, G. } \\
\text { garnettii }\end{array}$ & - & - & - & - & Yes & Loud call & Masters 1991 \\
\hline $\begin{array}{l}\text { Galago } \\
\text { senegalensis, G. } \\
\text { moholi }\end{array}$ & - & - & - & - & Yes & 14 calls & $\begin{array}{l}\text { Zimmermann } \\
1988\end{array}$ \\
\hline Gorilla gorilla & Yes & - & - & - & - & 8 calls & $\begin{array}{l}\text { Salmi et al. } \\
2014\end{array}$ \\
\hline Hylobates muelleri & Yes & - & No & - & - & Great call & Clink et al. 2017 \\
\hline Hylobates muelleri & Yes & - & Yes & - & - & Great call & Clink et al. 2018 \\
\hline Lepilemur spp. (10) & - & - & Yes & - & - & Loud call & $\begin{array}{l}\text { Méndez- } \\
\text { Cárdenas et al. } \\
2008\end{array}$ \\
\hline Microcebus spp. (3) & - & - & - & - & Yes & $\begin{array}{l}\text { Whistle, Purr, } \\
\text { Chitter }\end{array}$ & $\begin{array}{l}\text { Hending et al. } \\
2017\end{array}$ \\
\hline Microcebus spp. (3) & - & - & - & - & Yes & $\begin{array}{l}\text { Advertisement } \\
\text { call }\end{array}$ & $\begin{array}{l}\text { Braune et al. } \\
2008\end{array}$ \\
\hline $\begin{array}{l}\text { Microcebus } \\
\text { murinus }\end{array}$ & - & - & Yes & - & - & Trill & $\begin{array}{l}\text { Hafen et al. } \\
1998\end{array}$ \\
\hline Tarsius spp. (4) & - & - & - & - & Yes & $\begin{array}{l}\text { Loud call } \\
\text { (Duet call) }\end{array}$ & Nietsch 1999 \\
\hline Varecia variegata & - & - & - & Yes & - & Loud call & $\begin{array}{l}\text { Macedonia and } \\
\text { Taylor } 1985\end{array}$ \\
\hline
\end{tabular}


Max power

Center time

Q1 time

Q3 time

Table 2 Name and description of acoustic parameters measured. Not all parameters were included in discriminant function analysis because of redundancy.

Parameters Description

$$
\begin{array}{ll}
\text { Low frequency }(\mathrm{Hz}) & \text { The lower frequency bound of the selection } \\
\text { High frequency }(\mathrm{Hz}) & \text { The upper frequency bound of the selection }
\end{array}
$$$$
\text { Bandwidth } 90 \% \text { The difference between the } 5 \% \text { and } 95 \% \text { frequencies }
$$

Energy $(\mathrm{dB}) \quad$ The total energy within the selection bounds

Dur90\% The difference between 5\% and 95\% times

Delta frequency $(\mathrm{Hz})$ The difference between the upper and lower frequency limits of the selection

Peak frequency The frequency at which max power occurs within the selection

Delta time (s) The difference between the begin and end time for the selection

Center frequency $(\mathrm{Hz})$ The frequency that divides the selection into two frequency intervals of equal energy

Q1 frequency $(\mathrm{Hz}) \quad$ The frequency that divides the selection into two frequency intervals containing $25 \%$ and $75 \%$ of the energy in the selection

Q3 frequency $(\mathrm{Hz}) \quad$ The frequency that divides the selection into two frequency intervals containing $75 \%$ and $25 \%$ of the energy in the selection

The maximum power in the selection.

Frequency 5\%

The frequency that divides the selection into two frequency intervals containing $5 \%$ and $95 \%$ of the energy in the selection

Frequency $95 \%$

The frequency that divides the selection into two frequency intervals containing $95 \%$ and $5 \%$ of the energy in the selection

The point in time at which the selection is divided into two time intervals of equal energy

The point in time that divides the selection into two time intervals containing $25 \%$ and $75 \%$ of the energy in the selection

The point in time that divides the selection into two time intervals containing $75 \%$ and $25 \%$ of the energy in the selection

IQR duration (s)

Time 5\%

Time $95 \%$

Max time
The difference between the $1^{\text {st }}$ and $3^{\text {rd }}$ quartile times

The point in time that divides the selection into two time intervals containing 5\% and 95\% of the energy in the selection

The point in time that divides the selection into two time intervals containing $95 \%$ and $5 \%$ of the energy in the selection

The first time in the selection at which a spectrogram point with power equal to max power occurs

Quantitative acoustic characteristics analyzed (Raven). 
401

402

403

404

405

406

407

408

409

410

411

412

413

414

415

416

417

418

419

420

421

422

423

424

425

426

427

428

Table 3 All Aotus nigriceps vocal measurements were found to have significant $(p<0.001)$ inter-group differences. Post-hoc analysis was conducted using multiple comparisons of mean ranks with Bonferroni adjustment. All associations significant at $\mathrm{p}<0.05$.

\begin{tabular}{cll} 
Call Measurement & Group & Significant Associations (p value) \\
\hline Ch Ch & & \\
Dur90\% & A & $\mathrm{C}(0.00) ; \mathrm{D}(0.04)$ \\
& B & $\mathrm{C}(0.00) ; \mathrm{D}(0.01)$ \\
High frequency & C & $\mathrm{E}(0.00) ; \mathrm{F}(0.01) ; \mathrm{T} 2 \mathrm{~A}(0.00)$ \\
& A & $\mathrm{C}(0.00) ; \mathrm{D}(0.02) ; \mathrm{T} 2 \mathrm{~A}(0.00)$ \\
& B & $\mathrm{C}(0.00) ; \mathrm{D}(0.04) ; \mathrm{T} 2 \mathrm{~A}(0.00)$ \\
& C & $\mathrm{E}(0.00) ; \mathrm{F}(0.00) ; \mathrm{H}(0.01)$ \\
& D & $\mathrm{E}(0.01) ; \mathrm{F}(0.01) ; \mathrm{T} 9 \mathrm{~A}(0.05)$ \\
& E & $\mathrm{T} 2 \mathrm{~A}(0.00)$ \\
Low frequency & F & $\mathrm{T} 2 \mathrm{~A}(0.00)$ \\
& B & $\mathrm{B}(0.00) ; \mathrm{D}(0.03) ; \mathrm{T} 2 \mathrm{~A}(0.00)$ \\
& B & $\mathrm{C}(0.00) ; \mathrm{D}(0.00) ; \mathrm{E}(0.00) ; \mathrm{T} 2 \mathrm{~A}(0.00)$ \\
Bandwidth $90 \%$ & A & $\mathrm{B}(0.00) ; \mathrm{E}(0.00)$ \\
& B & $\mathrm{C}(0.00) ; \mathrm{E}(0.00) ; \mathrm{F}(0.00) ; \mathrm{H}(0.00) ; \mathrm{T} 2 \mathrm{~A}(0.00) ; \mathrm{TSH}(0.00)$ \\
& E & T2A $(0.00)$ \\
& TSH & $\mathrm{T} 9 \mathrm{~A}(0.04)$
\end{tabular}

Squeak

Dur90\%

A $\quad \mathrm{B}(0.00) ; \mathrm{E}(0.01) ; \mathrm{TSH}(0.00)$

B $\quad \mathrm{C}(0.02) ; \mathrm{E}(0.00) ; \mathrm{T} 2 \mathrm{~A}(0.00) ; \mathrm{TSH}(0.00)$

C $\quad \mathrm{E}(0.00) ; \mathrm{TSH}(0.00)$

E $\quad \mathrm{H}(0.00) ; \mathrm{T} 2 \mathrm{~A}(0.00) ; \mathrm{TSH}(0.00) ; \mathrm{T} 9 \mathrm{~A}(0.05)$

$\mathrm{H} \quad \mathrm{TSH}(0.00)$

T2A $\quad$ TSH $(0.00)$

High frequency $\quad$ A

$\mathrm{C}(0.03) ; \mathrm{E}(0.00) ; \mathrm{H}(0.00) ; \mathrm{TSH}(0.02)$

$\mathrm{C}(0.00) ; \mathrm{E}(0.00) ; \mathrm{H}(0.00) ; \mathrm{TSH}(0.00)$

$\begin{array}{ll}\mathrm{B} & \mathrm{C}(0.00) ; \mathrm{E}(0.00) ; \mathrm{H}(0.00) ; \mathrm{TSH} \\ \mathrm{C} & \mathrm{E}(0.00) ; \mathrm{H}(0.00) ; \mathrm{T} 2 \mathrm{~A}(0.00)\end{array}$

D $\quad \mathrm{TSH}(0.04)$

E $\quad \mathrm{H}(0.00) ; \mathrm{T} 2 \mathrm{~A}(0.00) ; \mathrm{TSH}(0.00)$

$\mathrm{H} \quad \mathrm{T} 2 \mathrm{~A}(0.00) ; \mathrm{TSH}(0.00)$

Low frequency $\quad \mathrm{A} \quad \mathrm{B}(0.00) ; \mathrm{E}(0.00)$

B $\quad \mathrm{C}(0.00) ; \mathrm{D}(0.01) ; \mathrm{E}(0.00) ; \mathrm{H}(0.00) ; \mathrm{T} 2 \mathrm{~A}(0.00) ; \mathrm{TSH}(0.00) ; \mathrm{T} 9 \mathrm{~A}(0.00)$

C $\quad \mathrm{T} 2 \mathrm{~A}(0.00)$

$\mathrm{E} \quad \mathrm{T} 2 \mathrm{~A}(0.00)$

$\mathrm{H} \quad \mathrm{T} 2 \mathrm{~A}(0.00)$

Bandwidth $90 \% \quad$ A

$\mathrm{B}(0.00) ; \mathrm{E}(0.00) ; \mathrm{H}(0.00) ; \mathrm{TSH}(0.01)$

B $\mathrm{C}(0.00) ; \mathrm{E}(0.00) ; \mathrm{H}(0.00) ; \mathrm{T} 2 \mathrm{~A}(0.00)$

C $\quad \mathrm{E}(0.00) ; \mathrm{H}(0.00) ; \mathrm{T} 2 \mathrm{~A}(0.00)$

E T2A(0.00); $\mathrm{TSH}(0.00)$

$\mathrm{H} \quad \mathrm{T} 2 \mathrm{~A}(0.01) ; \mathrm{TSH}(0.00)$ 
430

431

432

433

434

435

436

437

438

439

440

441

442

443

444

445

446

447

448

449

450

451

452

453

454

455

456

457

458

459

\begin{tabular}{lllllllll} 
Group & \% Correct & A & B & C & E & H & T2A & TSH \\
\hline A & 66.7 & $\mathbf{6}$ & 0 & 3 & 0 & 0 & 0 & 0 \\
B & 75.0 & 4 & $\mathbf{1 2}$ & 0 & 0 & 0 & 0 & 0 \\
C & 78.6 & 0 & 2 & $\mathbf{1 1}$ & 1 & 0 & 0 & 0 \\
E & 89.9 & 4 & 1 & 0 & $\mathbf{6 2}$ & 1 & 1 & 0 \\
H & 75.0 & 0 & 0 & 0 & 2 & $\mathbf{6}$ & 0 & 0 \\
T2A & 44.4 & 3 & 0 & 0 & 1 & 0 & $\mathbf{4}$ & 1 \\
TSH & 75.0 & 0 & 0 & 1 & 0 & 0 & 0 & $\mathbf{3}$ \\
\hline
\end{tabular}

460

Ch Ch alone

\begin{tabular}{lllllllll} 
Group & \% Correct & A & B & C & E & F & H & T2A \\
\hline A & 100 & $\mathbf{7}$ & 0 & 0 & 0 & 0 & 0 & 0 \\
B & 83.3 & 2 & $\mathbf{1 0}$ & 0 & 0 & 0 & 0 & 0 \\
C & 83.3 & 0 & 1 & $\mathbf{5}$ & 0 & 0 & 0 & 0 \\
E & 66.7 & 3 & 1 & 0 & $\mathbf{1 0}$ & 0 & 0 & 1 \\
F & 0 & 1 & 1 & 0 & 0 & $\mathbf{0}$ & 0 & 0 \\
H & 0 & 0 & 0 & 0 & 1 & 0 & $\mathbf{0}$ & 1 \\
T2A & 90.9 & 0 & 0 & 0 & 1 & 0 & 0 & $\mathbf{1 0}$ \\
\hline
\end{tabular}

\begin{tabular}{llll} 
Call Measurement & Wilks' Lambda & Partial Lambda & p valu \\
\hline Squeak & & & \\
Bandwidth 90\% & 0.07 & 0.85 & 0.00 \\
Energy & 0.06 & 0.92 & 0.00 \\
Dur90\% & 0.07 & 0.82 & 0.00 \\
Frequency 95\% & 0.06 & 0.88 & 0.00 \\
Max power & 0.06 & 0.89 & 0.00 \\
IQR duration & 0.06 & 0.96 & 0.00 \\
Center frequency & 0.06 & 0.98 & 0.00 \\
Q1 frequency & 0.06 & 0.93 & 0.00 \\
IQR bandwidth & 0.06 & 0.90 & 0.00 \\
Max time & 0.06 & 0.88 & 0.00 \\
& & & \\
Ch Ch & & & 0.00 \\
Energy & 0.17 & 0.33 & 0.00 \\
Dur90\% & 0.06 & 0.94 & 0.00 \\
Bandwidth 90\% & 0.05 & 0.96 & 0.00 \\
IQR duration & 0.06 & 0.89 & 0.00 \\
Frequency 95\% & 0.06 & 0.65 & 0.00 \\
Center frequency & 0.09 & 0.77 & 0.00 \\
Delta frequency & 0.07 & 0.79 & 0.00 \\
Q1 frequency & 0.07 & &
\end{tabular}

Squeak alone

Table 4 Stepwise discriminant function analysis of all non-redundant measured acoustic parameters.

Table 5 Discriminant function analysis correct classification utilizing 10-fold cross validation at group level.

461

462

463

464 
465

466

467

468

469

470

471

472

473

474

475

476

477

478

479

480

481

482

483

484

485

486

487

488

489

490

491

492

493

494

495

496

497

498

499

500

501

502

503

504

505

506

507

508

509
Table 6 Mann Whitney results comparing group acoustic parameters between distant locations ( 10km). Sample size (Ch Ch: CREES 108 and VC 441) and (Squeak: CREES 136 and VC 1150). *All associations significant at $\mathrm{p}<0.05$.

\begin{tabular}{|c|c|c|c|c|}
\hline Call Measurement & CREES Mean & VC Mean & $\mathrm{U}$ & P-value \\
\hline \multicolumn{5}{|l|}{ Squeak } \\
\hline Low Frequency & 1896 & 1557 & 41532 & $0.00 *$ \\
\hline High Frequency & 2905 & 2715 & 48217 & $0.00 *$ \\
\hline Bandwidth $90 \%$ & 737 & 633 & 57946 & $0.00 *$ \\
\hline Energy $(\mathrm{dB})$ & 75 & 89 & 51471 & $0.00 *$ \\
\hline Dur90\% & 0.036 & 0.28 & 50231 & $0.00 *$ \\
\hline Peak Frequency & 2577 & 2395 & 47752 & $0.00 *$ \\
\hline Delta Time & 0.049 & 0.041 & 51588 & $0.00 *$ \\
\hline Center Frequency & 2525 & 2370 & 40555 & $0.00 *$ \\
\hline Q1 Frequency & 2341 & 2242 & 56039 & $0.00 *$ \\
\hline Q3 Frequency & 2687 & 2477 & 37523 & $0.00 *$ \\
\hline Frequency $5 \%$ & 2079 & 1951 & 71783 & 0.11 \\
\hline IQR Duration & 0.02 & 0.015 & 51031 & $0.00 *$ \\
\hline Max Time & 99 & 222 & 47045 & $0.00 *$ \\
\hline \multicolumn{5}{|l|}{$C h C h$} \\
\hline Low Frequency & 2504 & 1497 & 12490 & $0.00 *$ \\
\hline High Frequency & 12901 & 11268 & 13405 & $0.00 *$ \\
\hline Bandwidth $90 \%$ & 4991 & 4263 & 16333 & $0.00 *$ \\
\hline Energy (dB) & 112 & 88 & 11554 & $0.00 *$ \\
\hline Dur90\% & 0.03 & 0.03 & 23617 & 0.89 \\
\hline Peak Frequency & 5904 & 5596 & 20661 & $0.03 *$ \\
\hline Delta Time & 0.04 & 0.04 & 23239 & 0.70 \\
\hline Center Frequency & 5703 & 5541 & 23653 & 0.91 \\
\hline Q1 Frequency & 4585 & 4740 & 17581 & $0.00 *$ \\
\hline Q3 Frequency & 6810 & 6235 & 18448 & $0.00 *$ \\
\hline Center Time & 376 & 98 & 8585 & $0.00 *$ \\
\hline IQR Duration (s) & 0.02 & 0.02 & 23220 & 0.68 \\
\hline Frequency $5 \%$ & 3255 & 3215 & 20142 & $0.01 *$ \\
\hline
\end{tabular}

